\title{
Apheresis therapies for NMOSD attacks
}

\section{A retrospective study of 207 therapeutic interventions}

Ingo Kleiter, MD, Anna Gahlen, MD, Nadja Borisow, MD, Katrin Fischer, MD, Klaus-Dieter Wernecke, PhD, Kerstin Hellwig, MD, Florence Pache, MD, Klemens Ruprecht, MD, Joachim Havla, MD, Tania Kümpfel, MD, Orhan Aktas, MD, Hans-Peter Hartung, MD, Marius Ringelstein, MD, Christian Geis, MD, Christoph Kleinschnitz, MD, Achim Berthele, MD, Bernhard Hemmer, MD, Klemens Angstwurm, MD, Jan-Patrick Stellmann, MD,

Simon Schuster, MD, Martin Stangel, MD, Florian Lauda, MD, Hayrettin Tumani, MD, Christoph Mayer, MD, Markus Krumbholz, MD, Lena Zeltner, MD, Ulf Ziemann, MD, Ralf Linker, MD, Matthias Schwab, MD, Martin Marziniak, MD, Florian Then Bergh, MD, Ulrich Hofstadt-van Oy, MD, Oliver Neuhaus, MD, Uwe K. Zettl, MD, Jürgen Faiss, MD, Brigitte Wildemann, MD, Friedemann Paul, MD, Sven Jarius, MD, and Corinna Trebst, MD, on behalf of NEMOS (Neuromyelitis Optica Study Group)

Neurol Neuroimmunol Neuroinflamm 2018;5:e504. doi:10.1212/NXI.0000000000000504

\section{Abstract}

\section{Objective}

To analyze whether 1 of the 2 apheresis techniques, therapeutic plasma exchange (PE) or immunoadsorption (IA), is superior in treating neuromyelitis optica spectrum disorder (NMOSD) attacks and to identify predictive factors for complete remission (CR).

\section{Methods}

This retrospective cohort study was based on the registry of the German Neuromyelitis Optica Study Group, a nationwide network established in 2008. It recruited patients with neuromyelitis optica diagnosed according to the 2006 Wingerchuk criteria or with aquaporin-4 (AQP4-ab)-antibody-seropositive NMOSD treated at 6 regional hospitals and 16 tertiary referral centers until March 2013. Besides descriptive data analysis of patient and attack characteristics, generalized estimation equation (GEE) analyses were applied to compare the effectiveness of the 2 apheresis techniques. A GEE model was generated to assess predictors of outcome.

\section{Results}

Two hundred and seven attacks in 105 patients (87\% AQP4-ab-antibody seropositive) were treated with at least 1 apheresis therapy. Neither PE nor IA was proven superior in the therapy of NMOSD attacks. CR was only achieved with early apheresis therapy. Strong predictors for CR were the use of apheresis therapy as first-line therapy (OR 12.27, 95\% CI: 1.04-144.91, $p=$ 0.047 ), time from onset of attack to start of therapy in days (OR 0.94, 95\% CI: 0.89-0.99, $p=0.014$ ), the presence of AQP4-abantibodies (OR 33.34, 95\% CI: 1.76-631.17, $p=0.019$ ), and monofocal attack manifestation (OR 4.71, 95\% CI: 1.03-21.62, $p=$ 0.046).

\section{Conclusions}

Our findings suggest early use of an apheresis therapy in NMOSD attacks, particularly in AQP4-ab-seropositive patients. No superiority was shown for one of the 2 apheresis techniques.

\section{Classification of evidence}

This study provides Class IV evidence that for patients with NMOSD, neither PE nor IA is superior in the treatment of attacks.

\section{Correspondence}

Dr. Kleiter

ingo.kleiter@rub.de
RELATED ARTICLE

\section{Editorial}

Plasmapheresis for acute attacks in neuromyelitis optica spectrum disorders

Page e510

\section{MORE ONLINE}

\section{$\rightarrow$ Class of Evidence}

Criteria for rating therapeutic and diagnostic studies

NPub.org/coe

\begin{abstract}
From the Department of Neurology (I.K., A.G., K.H.), St. Josef Hospital, Ruhr University Bochum; Marianne-Strauß-Klinik (I.K.), Behandlungszentrum Kempfenhausen für Multiple Sklerose Kranke, Berg; NeuroCure Clinical Research Center and Experimental and Clinical Research Center (N.B., F. Pache), Charité Universitätsmedizin Berlin, and Max Delbrueck Center for Molecular Medicine, Berlin; Department of Neurology (K.F., J.F.), Asklepios Fachklinikum Teupitz; CRO Sostana GmbH and Charité Universitätsmedizin Berlin (K.-D.W.); Department of Neurology and Clinical and Experimental Multiple Sclerosis Research Center (F.Pache, K.R.), Charité Universitätsmedizin Berlin; Institute of Clinical Neuroimmunology (J.H., T.K.), Ludwig Maximilians University, Munich; Department of Neurology (O.A., H.-P.H., M.R.), Medical Faculty, Heinrich Heine University Düsseldorf; Department of Neurology (C.G., M. Schwab), Jena University Hospital; Department of Neurology (C.K.), University Hospital Essen; Department of Neurology (A.B.), Klinikum rechts der Isar, Technische Universität München, Munich; Department of Neurology (B.H.), Klinikum rechts der Isar, Technische Universität München and Munich Cluster for Systems Neurology (SyNergy); Department of Neurology (K.A.), University Hospital Regensburg; Institute of Neuroimmunology and MS (INIMS) and Department of Neurology (J.-P.S.), University Medical Centre Hamburg-Eppendorf, HamburgKlinik und Poliklinik für Neurologie (S.S.), Universitätsklinikum Hamburg-Eppendorf; Clinical Neuroimmunology and Neurochemistry (M. Stangel), Department of Neurology, Hannover Medical School; Department of Neurology (F.L., H.T.), University of Ulm; Fachklinik für Neurologie Dietenbronn (H.T.), Akademisches Krankenhaus der Universität Ulm, Schwendi; Department of Neurology (C.M.), Goethe University Frankfurt; Department of Neurology \& Stroke (M.K., L.Z., U. Ziemann), and Hertie-Institute for Clinical Brain Research, University of Tübingen; Department of Neurology (R.L.), FriedrichAlexander University Erlangen-Nuremberg; Department of Neurology and Neurological Intensive Care (M.M.), Isar-Amper-Clinic, Munich-East, Haar; Department of Neurology (F.T.B.), University of Leipzig; Department of Neurology (U. Hofstadt-van Oy), Klinikum Westfalen, Dortmund; Department of Neurology (O.N.), SRH Krankenhaus Sigmaringen; Neuroimmunological Section (U. Zettl), Department of Neurology, University of Rostock; Molecular Neuroimmunology Group (B.W., S.J.), Department of Neurology, University of Heidelberg; NeuroCure Clinical Research Center (F. Paul), Charité Universitätsmedizin Berlin, corporate member of Freie Universität Berlin, Humboldt-Universität zu Berlin, and Berlin Institute of Health, and Experimental and Clinical Research Center, Max Delbrück Center for Molecular Medicine and Charité-Universitätsmedizin Berlin; and Department of Neurology (C.T.), Hannover Medical School, Germany. Funding information and disclosures are provided at the end of the article. Full disclosure form information provided by the authors is available with the full text of this article at Neurology.org/NN.
\end{abstract}

NEMOS (Neuromyelitis Optica Study Group) coinvestigators are listed in the appendix at the end of the article.

The Article Processing Charge was funded by the authors.

This is an open access article distributed under the terms of the Creative Commons Attribution-NonCommercial-NoDerivatives License 4.0 (CC BY-NC-ND), which permits downloading and sharing the work provided it is properly cited. The work cannot be changed in any way or used commercially without permission from the journal. 


\section{Glossary}

AQP4-ab = aquaporin-4; CR = complete remission; EDSS = Expanded Disability Status Scale; GEE = generalized estimating equation; IA = immunoadsorption; IQR = interquartile range; NEMOS = Neuromyelitis Optica Study Group; NMOSD = neuromyelitis optica spectrum disorder; $\mathbf{N R}=$ no remission; $\mathbf{O N}$ = optic neuritis; $\mathbf{P E}=$ plasma exchange; $\mathbf{P R}=$ partial remission.

Adequate treatment of attacks in neuromyelitis optica spectrum disorders (NMOSDs) is crucial as long-term disability in these patients is accumulated by poor recovery from attacks. ${ }^{1,2}$ We have previously shown in a retrospective analysis that aggressive treatment of attacks, particularly escalation of attack therapy, can improve the attack outcome with the sequence of treatments being crucial. ${ }^{3}$ In particular, our study suggested that first-line therapy with apheresis therapies may be superior to high-dose steroid pulse therapy in attacks involving the spinal cord.

Apheresis therapies aim to eliminate pathogenic antibodies and other proinflammatory factors from the patient's circulation. Two major techniques are used. Therapeutic plasma exchange (PE) separates patient's plasma from the whole blood. ${ }^{4}$ Centrifugation devices or highly permeable filters are used to separate the plasma filtrate with molecules up to 1,000 $\mathrm{kD}$, including immunoglobulins, complement factors, and albumin from blood cells. The plasma filtrate is discarded, and either $5 \%$ albumin solution or fresh-frozen plasma is added to the filtered blood before reinfusion. For immunoadsorption (IA), plasma separation is equally needed as the first step. ${ }^{5}$ The plasma fraction is then passed through an IA device. Single-pass devices use tryptophan as an adsorber, whereas reusable devices use in most cases the Staphylococcus aureus cell wall-derived protein A. Several plasma constituents, including immunoglobulins and complement, are removed from the plasma, whereas albumin and clotting factors are mostly spared and reinfused. Besides the immediate intravasal reduction of autoantibodies, e.g., those targeting aquaporin-4 (AQP4-ab), ${ }^{6} \mathrm{PE}$ and IA also show effects on immunoglobulin redistribution and subsequent immunomodulatory changes. ${ }^{7-10}$

It remains to be elucidated whether one of the apheresis therapies might be superior in the treatment of NMOSD attacks. We therefore conducted a retrospective analysis of 207 NMOSD attacks in 105 patients who were treated either with PE or IA and aimed to identify predictive factors for a favorable therapeutic response.

\section{Methods}

\section{Study design}

This retrospective cohort study is based on data of the registry of the German Neuromyelitis Optica Study Group (NEMOS, nemos-net.de). Final data entry varied across centers and was performed between January 2012 and March 2013. At this time, the registry contained 215 patients with both NMO diagnosed according to the 2006 Wingerchuk criteria ${ }^{11}$ and AQP4-ab-seropositive NMOSD. ${ }^{12}$

Previously, we identified and characterized 1,124 attacks in 186 patients with NMO and NMOSD, treated at 6 regional hospitals and 16 tertiary referral centres. ${ }^{3}$ Of these, all attacks treated with an apheresis therapy, PE or IA, were included in this subgroup analysis. Twelve centers used both PE and IA, 9 centers used only PE, and 1 center used only IA. Further details on data collection, quality, and processing can be found in the original characterization of the cohort. ${ }^{3}$

For each patient, demographic and diagnostic data, as well as the number and dates of acute attacks from disease onset to last follow-up, were included in the analysis. Moreover, attackrelated clinical features (Expanded Disability Status Scale [EDSS] and visual acuity were available) and information on attack treatment and outcome were assessed from the patient records. The definition of an attack followed the definition used for MS relapses: an objective neurologic worsening lasting for at least 24 hours in the absence of fever or infections and occurring more than 30 days after the previous attack. All attacks were confirmed by neurologic examination.

$\mathrm{PE}$ and IA were conducted according to local standard procedures. IA was performed using tryptophan (TR-350; Diamed Medizintechnik $\mathrm{GmbH}$ ) or protein A (Immunosorba; Fresenius Medical Care) as an adsorber. One apheresis treatment course was defined as at least 3 therapeutic PEs or at least 3 IAs.

Short-term remission status of attack-related neurologic deficits was chosen as the primary outcome parameter and rated as complete remission (CR) when there was full recovery, partial remission (PR) when there was incomplete recovery, and no remission (NR) when there was no improvement at all of the attack-related neurologic deficits in relation to the therapy cycle. The remission status was evaluated immediately after the end of the apheresis therapy.

The primary research question was to evaluate whether PE or IA was more beneficial for NMOSD attack therapy. Given its retrospective nature, this study was expected to provide Class IV evidence.

\section{Standard protocol approvals, registrations, and patient consents}

Ethics approval was obtained from the Institutional Review Board of the Ruhr University Bochum (\#4573-13) and of the participating centers. Patients provided written informed 
consent. The study was performed according to ICH/GCP and current German legal requirements; it was not registered because registration was neither required nor available for retrospective, noninterventional studies at the time of data collection.

\section{Statistical analysis}

Patient characteristics were descriptively analyzed. Comparison of the use as first-line or consecutive treatment of $\mathrm{PE}$ and IA, as well as distribution among treatment courses and clinical attack manifestation, was performed using the exact $\chi^{2}$ test. Generalized estimating equations (GEEs) ${ }^{13}$ with remission status (CR vs PR or NR) of attacks as the dependent variable were used for the analysis of direct comparisons of the effectiveness of PE vs IA in the first- or second-line use. ORs with $95 \% \mathrm{CIs}$ and corresponding $p$ values were given. GEE analyses with the same dependent variable were also used to identify predictors of outcome. The following variables were analyzed: sex, age at attack, time from onset of disease to attack, AQP4-status, NMO vs NMOSD, clinical manifestation (absence or presence of myelitis, isolated manifestation of optic neuritis [ON] or myelitis vs simultaneous), disease-modifying immunotherapy, time from onset of attack to initiation of therapy, apheresis as first- vs second-line therapy, technique of therapy (PE vs IA), and center (to control for a center effect). We indicated missing data in the figure legends; the corresponding observations were dropped in the multivariate statistical analyses as usual. $p$ Values $<0.05$ were considered statistically significant. All tests were performed as exploratory data analysis, therefore, no adjustments for multiple testing were made. IBM SPSS Statistics, Version 24,
STATA (Data Analysis and Statistical Software; StataCorp LP) and StatXact 6 (CYTEL Software Corp) were used for computations and GraphPad Prism version 6.0f (GraphPad Software) for visualization.

\section{Data availability}

As far as permitted, according to data protection requirements and consent provided by the participants, original data are available from the corresponding author on request from any qualified investigator within 5 years after publication.

\section{Results}

\section{Demographic and clinical characteristics}

Among the initial 1,124 attacks in 186 patients, 253 attacks were excluded due to insufficient data, 42 were not treated, and 622 attacks did not receive an apheresis therapy (figure 1).

Two hundred and seven attacks in 105 patients were treated with apheresis therapies, of these 189 with a single apheresis therapy and 18 with multiple apheresis therapies. A total of $192 \mathrm{PE}$ (in 99 patients) and 38 IA procedures (in 23 patients), each with at least 3 exchanges, were examined. Patient and attack characteristics are given in table 1.

Apheresis therapies were applied as first-line choice in 72 attacks, as second-line (another attack therapy was given before the start of apheresis therapy) in 98 attacks, and as thirdline or later ( 2 or more previous attack therapies were given) in 37 attacks. Time from onset of attack to start of therapy was

Figure 1 Study flow chart

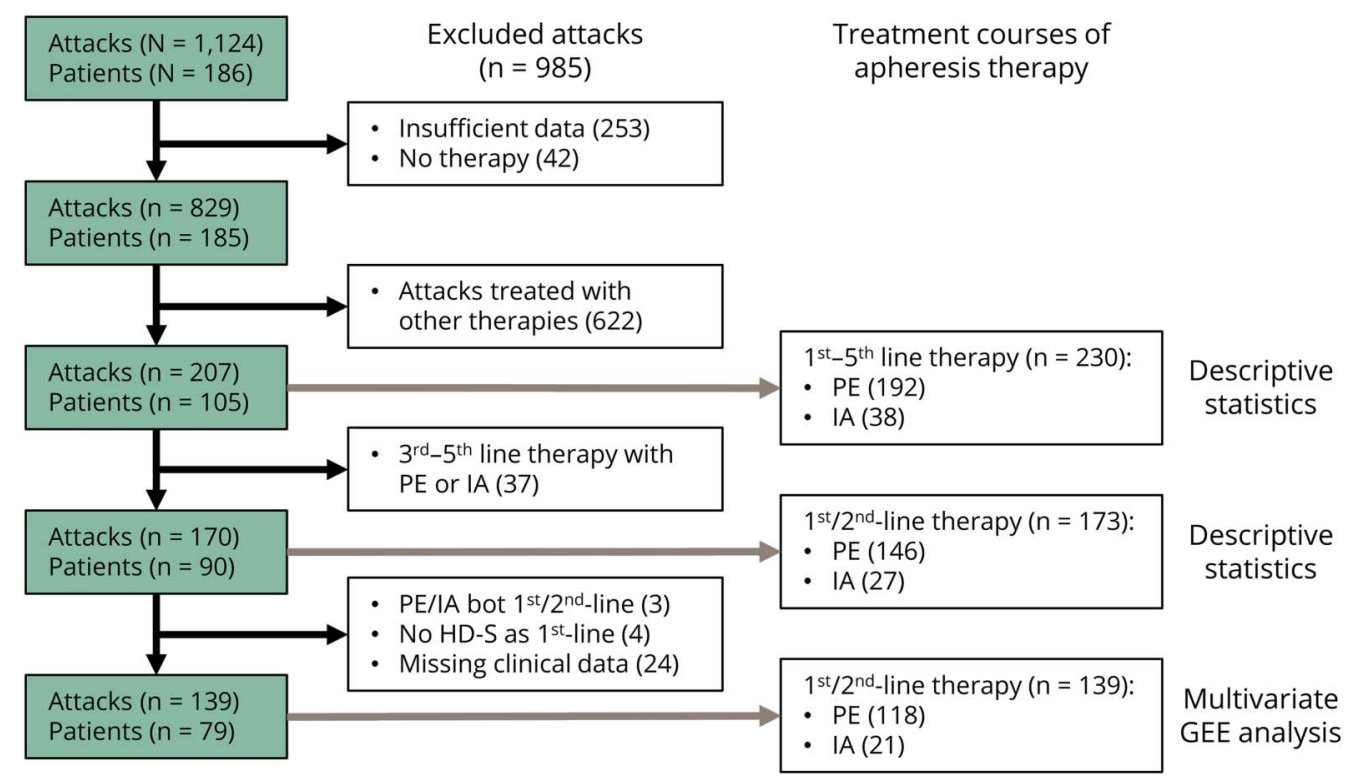

HD-S = high-dose IV steroids; IA = immunoadsorption; PE = plasma exchange. 
Table 1 Patient characteristics

\begin{tabular}{|c|c|}
\hline & Patients $(n=105)$ \\
\hline $\mathrm{NMO}^{\mathrm{a}}(\mathrm{n}, \%)$ & $84(80 \%)$ \\
\hline AQP4-ab positive NMOSDb $(n, \%)$ & $21(20 \%)$ \\
\hline Female sex (n, \%) & $82(78 \%)$ \\
\hline Age at onset (y; mean, SD) & $43.4(14.7)$ \\
\hline Disease onset to last visit (y; median, IQR) & $5.9(3.0-10.1)$ \\
\hline AQP4-ab positive ${ }^{c}(n, \%)$ & $91(87 \%)$ \\
\hline$\geq 1$ optic neuritis ever (n, \%) & $87(83 \%)$ \\
\hline$\geq 1$ myelitis ever $(n, \%)$ & $102(97 \%)$ \\
\hline Relapsing disease course $^{d}(n, \%)$ & $99(94 \%)$ \\
\hline Attacks/patient (n, IQR) & $5(3-8)$ \\
\hline ARR ( $n=97 ;$ median, IQR) & $0.91(0.63-1.46)$ \\
\hline \multicolumn{2}{|c|}{ 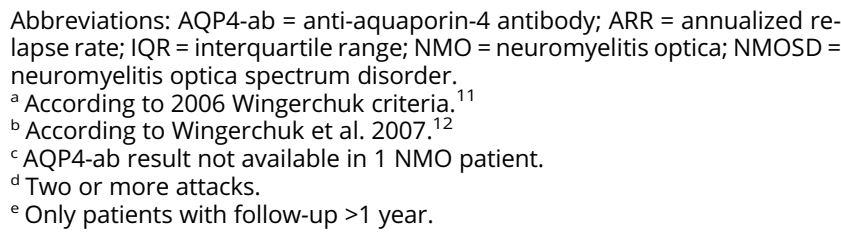 } \\
\hline
\end{tabular}

median 1 day (interquartile range $[\mathrm{IQR}] 0-4, \mathrm{n}=58$ ) in firstline therapy, 11.5 days (IQR 5.0-22.75, $\mathrm{n}=92$ ) in second-line therapy, and 15.5 days (IQR 10-45.75, $\mathrm{n}=32$ ) in third-line or later therapy. No difference between PE and IA usage was found in terms of distribution among lines of therapy ( $p=$
0.303, exact $\chi^{2}$ test) and clinical attack manifestation ( $p=$ 0.055 , exact $\chi^{2}$ test, figure 2 ).

\section{PE and IA are both effective in the therapy of NMOSD attacks}

Both PE and IA were effective and induced at least PR in most attacks when used as first- to fifth-line therapy (figure 3, A and B). Although attacks treated with IA always showed a clinical response as nonresponders were not found in this treatment group, we could not show a difference in efficacy between $\mathrm{PE}$ and IA ( $p=0.264$, GEE analysis, CR as the dependent variable) (figure 3C). There was also no difference for the change in EDSS between PE and IA (figure 3D). Because of overlapping effects of preceding attack therapies, we excluded third- to fifth-line apheresis therapies from this statistical analysis. Clinical characteristics of first- and second-line apheresis therapies are given in table 2 .

\section{The use of apheresis therapies as first-line and early therapy is associated with the highest remission rate}

CR was only reached with apheresis therapy initiated early (first- and second-line therapy in IA, first- to third-line therapy in PE). Forty percent of patients had CR when apheresis therapy was started without delay, i.e., day $0-2$ after onset of symptoms, but improvement declined stepwise with later treatment start (figure 3E). No patient completely recovered when apheresis therapy was commenced later than 20 days after symptom onset. CR was reached more often with early PE (start after symptom onset day 0-6: 29\%; day $\geq 7: 3.7 \%, n=$ 144 attacks) than with early IA treatment (start after symptom onset day 0-6: 6.7\%; day $\geq 7: 0 \%, \mathrm{n}=28$ attacks).

Figure 2 Overview of apheresis therapies

A

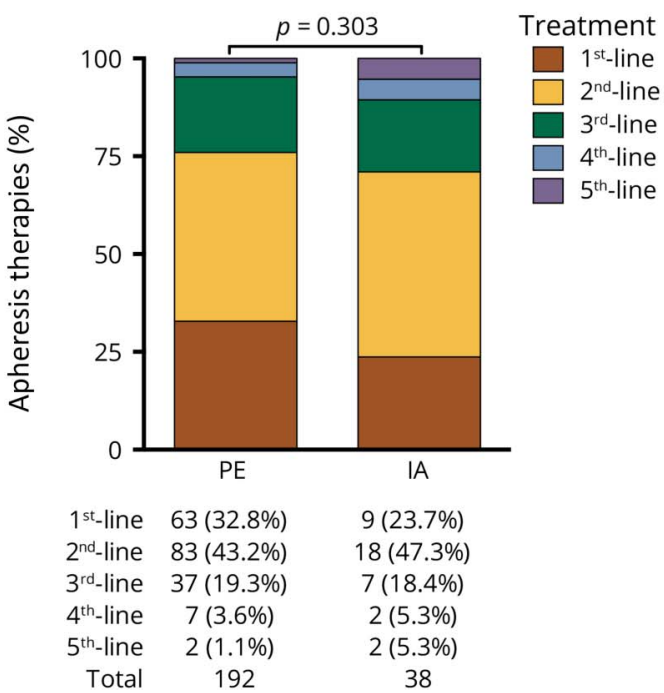

B

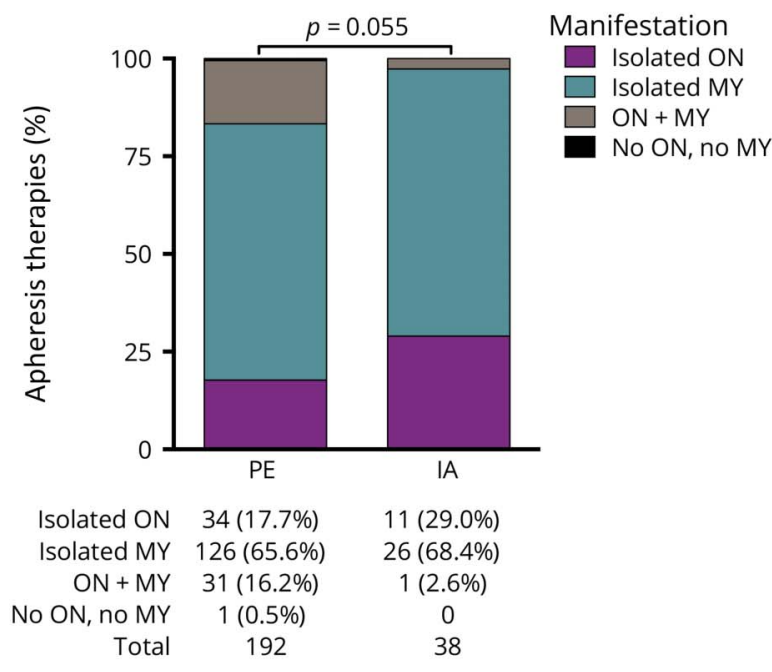

Plasma exchange and immunoadsorption were applied at similar frequencies for escalation from first- to fifth-line treatment (A) and for various clinical manifestations (B) of NMOSD attacks. The chi-square test was used for statistical analysis. IA = immunoadsorption; $\mathrm{MY}=\mathrm{myelitis} ; \mathrm{ON}=\mathrm{optic}$ neuritis; $\mathrm{PE}=$ plasma exchange. 
A. Remission status PE

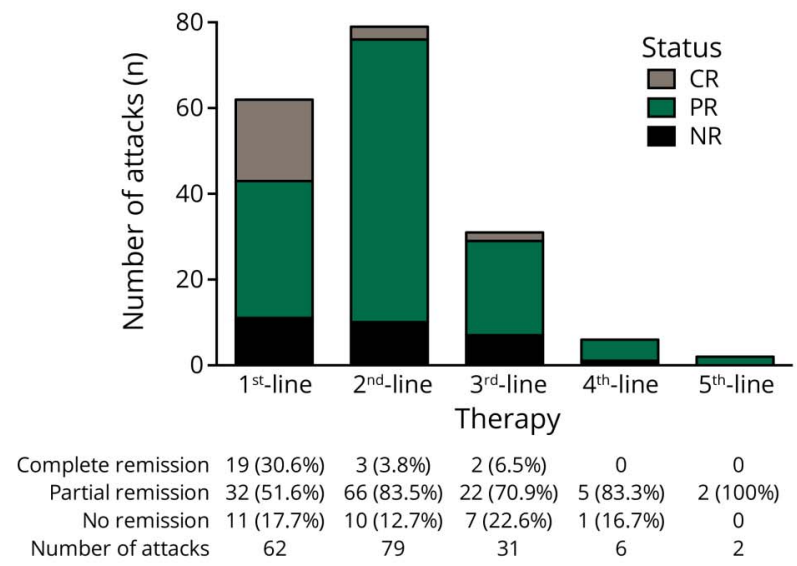

C. Remission status after $1^{\text {st- }}$ or $2^{\text {nd-line therapy }}$

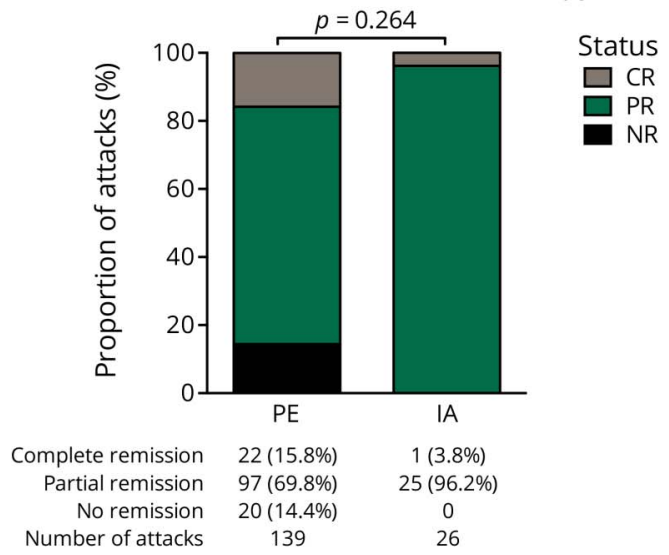

B. Remission status IA

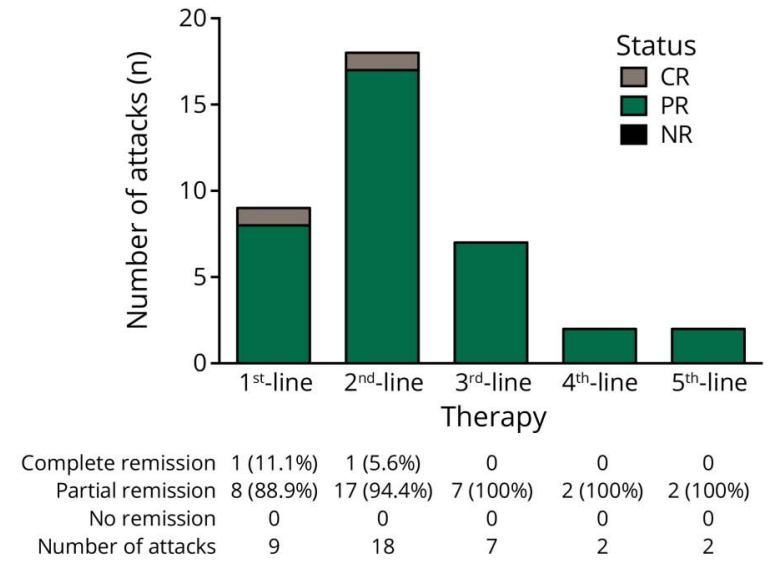

D. EDSS after $1^{\text {st }}$ or $2^{\text {nd }-l i n e ~ t h e r a p y ~}$

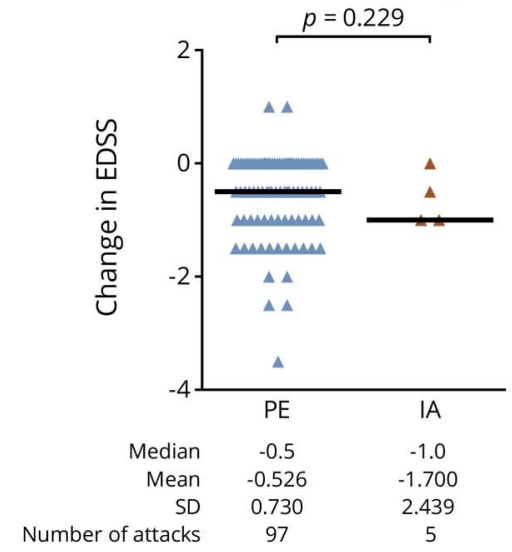

E. Remission status according to delay of PE or IA

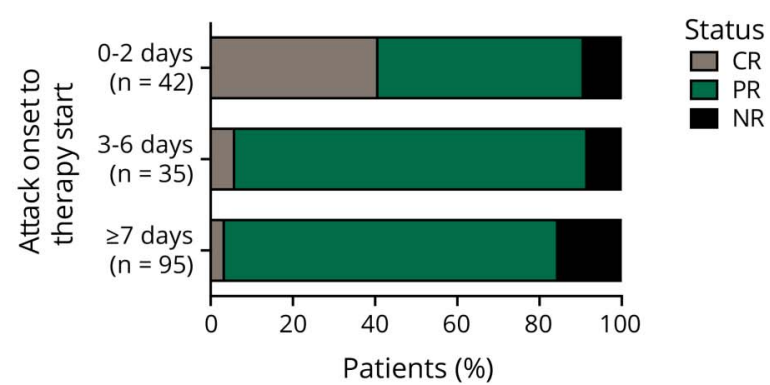

Remission status of all attacks (total $n=207$ ) treated with plasma exchange $(A)$ or immunoadsorption (B). Missing data plasma exchange: 1 st line, $n=1 ; 2 n d$ line, $n=4 ; 3 r$ line, $n=6$; and 4th line, $n=1$. (C) Short-term remission status after first- or second-line therapy with plasma exchange or immunoadsorption. Treatment courses with PE/IA as first- and second-line therapy were excluded $(n=2)$. Missing data plasma exchange: 1 st line, $n=1$ and $2 n d$ line, $n=4$. Generalized estimation equations with complete remission as the dependent variable were used for statistical analysis. (D) Change in EDSS after first or secondline therapy with plasma exchange (gray triangles) or immunoadsorption (red triangles). Missing data plasma exchange: $1 \mathrm{st}$ line, $n=19 ; 2 n d$ line, $n=30 ;$ missing data immunoadsorption: 1 st line, $n=7$ and 2 nd line, $n=15$. One out of range value (immunoadsorption, -6.0 ) is not shown. Generalized estimation equations were used for statistical analysis. The Median is highlighted as black line. (E) Short-term remission status after apheresis therapy according to time intervals of attack onset to start of therapy. $C R=$ complete remission; $I A=$ immunoadsorption; NR = no remission; $P E=$ plasma exchange; $P R=$ partial remission.

For multivariate GEE analyses of predictors of CR, we further excluded attacks that were treated with an apheresis therapy in both first and second line of treatment $(n=3)$, attacks where a second-line apheresis therapy was not preceded by high-dose steroids $(\mathrm{n}=4)$, and attacks with missing clinical information $(\mathrm{n}=24)$. Therefore, multivariate analyses were possible in 139 attacks in 79 patients (see flow chart figure 1).

Strong predictors for CR were the use of apheresis therapy as first-line therapy (OR 12.271; 95\% CI: 1.04-144.91, $p=0.047$ ), time from onset of attack to start of therapy in days (OR 0.937; 
Table 2 First- and second-line use of apheresis therapies for NMOSD attacks

\begin{tabular}{|c|c|c|c|c|c|c|}
\hline & \multicolumn{3}{|l|}{ First line $(n=72)$} & \multicolumn{3}{|l|}{ Second line $(n=101)$} \\
\hline & PE $(n=63)$ & IA $(n=9)$ & $\begin{array}{l}p \\
\text { Value }\end{array}$ & PE $(n=83)$ & IA $(n=18)$ & $\begin{array}{l}p \\
\text { Value }\end{array}$ \\
\hline \multicolumn{7}{|l|}{$\begin{array}{l}\text { Characteristics of attacks and } \\
\text { therapies }\end{array}$} \\
\hline Isolated optic neuritis (n, \%) & $10(15.9 \%)$ & $2(22.2 \%)$ & $0.879^{a}$ & $14(16.9 \%)$ & $6(33.3 \%)$ & $0.167^{a}$ \\
\hline Isolated myelitis (n, \%) & $44(69.8 \%)$ & $6(66.7 \%)$ & & $55(66.3 \%)$ & $12(66.7 \%)$ & \\
\hline$M Y+O N(n, \%)$ & $9(14.3 \%)$ & $1(11.1 \%)$ & & $13(15.7 \%)$ & 0 & \\
\hline Age at attack (y; mean, SD) & $44.9(16.3)$ & $38.2(7.7)$ & $0.192^{b}$ & $49.6(14.4)$ & $39.0(9.4)$ & $0.002^{\mathrm{b}}$ \\
\hline Disease duration (y; median, IQR) & $3.3(0.8-9.0)$ & $4.6(2.8-8.8)$ & $0.216^{\mathrm{b}}$ & $2.7(0.2-6.1)$ & $2.5(0.8-4.8)$ & $0.845^{\mathrm{b}}$ \\
\hline Attack number (median, IQR) & $6(3-12)$ & $4(3-8)$ & $0.411^{b}$ & $4(2-7)$ & $4(3-7)$ & $0.524^{b}$ \\
\hline $\begin{array}{l}\text { EDSS at start of therapy (median, } \\
\text { IQR) }\end{array}$ & $6.0(3.5-7.5)(n=50)$ & $8.5(4.5-9.5)(n=3)$ & $0.116^{\mathrm{b}}$ & $7.0(4.1-8.0)(n=56)$ & $5.8(3.9-7.1)(n=6)$ & $0.281^{\mathrm{b}}$ \\
\hline HD-S as first-line therapy $(n, \%)$ & NA & NA & NA & $77(92.8 \%)$ & $17(94.4 \%)$ & $0.800^{a}$ \\
\hline $\begin{array}{l}\text { Time from attack onset to start of } \\
\text { therapy (d; median, IQR) }\end{array}$ & $1(0-4)(n=52)$ & $1.5(0-18)(n=6)$ & $0.548^{b}$ & $13(6-23)(n=74)$ & $6(5-24)(n=18)$ & $0.321^{\mathrm{b}}$ \\
\hline No. of exchanges (median, IQR) & $5(5-8)(n=55)$ & $8(5.75-9)(n=6)$ & $0.020^{\mathrm{b}}$ & $5(5-7)(n=75)$ & $5(5-6)(n=17)$ & $0.552^{\mathrm{b}}$ \\
\hline $\begin{array}{l}\text { Plasma exchange volume per } \\
\text { session }(\mathrm{I} ; \text { median, IQR) }\end{array}$ & $3(2.5-3.5)(n=15)$ & $2(n=1)$ & NA & $2.5(2.35-3.5)(n=28)$ & $2(1.5-2.55)(n=9)$ & $0.063^{b}$ \\
\hline \multicolumn{7}{|l|}{ Characteristics of patients } \\
\hline Treated patients (n) & 28 & 7 & & 70 & 15 & \\
\hline NMO (n, \%) & $22(78.6 \%)$ & $6(85.7 \%)$ & $0.673^{a}$ & $55(78.6 \%)$ & $12(80 \%)$ & $0.902^{a}$ \\
\hline AQP4-ab positive NMOSD $(n, \%)$ & $6(21.4 \%)$ & $1(14.3 \%)$ & & $15(21.4 \%)$ & $3(20 \%)$ & \\
\hline Female sex $(n, \%)$ & $23(82.1 \%)$ & $6(85.7 \%)$ & $0.823^{\mathrm{a}}$ & $54(77.1 \%)$ & $13(86.7 \%)$ & $0.413^{\mathrm{a}}$ \\
\hline AQP4-ab positive (n, \%) & $26(92.9 \%)$ & $5(71.4 \%)$ & $0.111^{a}$ & $60(87 \%)$ & $15(100 \%)$ & $0.139^{a}$ \\
\hline
\end{tabular}

95\% CI: $0.89-0.99, p=0.014)$, and the presence of AQP4-abs (OR 33.338; 95\% CI: 1.76-631.17, $p=0.019$ ) (table 3). Monofocal attack manifestations were more likely to show CR than multifocal attacks (OR 4.709; 95\% CI: 1.03-21.62, $p=$ 0.046). Age (per year) was an intermediate predictor (OR 0.925; 95\% CI: $0.85-1.01, p=0.081)$ : the chance to have a CR of attack symptoms decreased with age by approximately $8 \%$ per year. Other factors such as apheresis technique, sex, center, diagnosis of NMO vs NMOSD, disease duration, or presence of disease-modifying immunotherapy did not predict CR.

\section{Discussion}

Two hundred and seven NMOSD attacks in 105 patients were identified in the NEMOS registry, which were all treated with an apheresis therapy (PE or IA). Confirming previous reports from smaller patient cohorts, ${ }^{14-22}$ both PE and IA were effective in the therapy of NMOSD attacks. We could not detect differences between the 2 apheresis techniques with regard to clinical outcome. Although techniques are different, both therapies aim at eliminating circulating antibodies from the patient's circulation. This is of particular importance in patients with NMOSD. Accordingly, our analysis revealed that the presence of serum AQP4-abs was a strong predictor for $\mathrm{CR}$ after apheresis therapies. This is in contrast to observations from other case series, where effectiveness of apheresis therapy was independent of the AQP4ab serostatus ${ }^{16,17,23}$ and supports the notion that AQP4-abs have direct pathogenic effects. Nevertheless, these differences have to be interpreted with caution as endpoints in these case series were different. Moreover, the analyzed number of seropositive patients in our GEE analysis was more than 10 
Table 3 Factors associated with complete remission from NMOSD attacks after apheresis therapy

\begin{tabular}{lll}
\hline & \multicolumn{2}{l}{ Multivariate analysis } \\
\cline { 2 - 3 } & $\boldsymbol{p}$ Value & OR (95\% CI) \\
\hline Female sex (vs. male) & 0.456 & $3.447(0.13-89.40)$ \\
\hline Age at attack (per 1 y) & 0.081 & $0.925(0.85-1.01)$ \\
\hline $\begin{array}{l}\text { Time from onset of disease to } \\
\text { attack (per 1 y) }\end{array}$ & 0.247 & $0.926(0.81-1.06)$ \\
\hline AQP4-ab positive (vs negative) & $\mathbf{0 . 0 1 9}$ & $\mathbf{3 3 . 3 3 8}(\mathbf{1 . 7 6 - 6 3 1 . 1 7 )}$ \\
\hline $\begin{array}{l}\text { NMO (vs NMOSD) } \\
\text { MY present (vs absent) }\end{array}$ & 0.316 & $2.951(0.36-24.41)$ \\
\hline $\begin{array}{l}\text { Isolated ON or MY (vs } \\
\text { simultaneous ON + MY) }\end{array}$ & 0.726 & $1.350(0.25-7.2)$ \\
\hline $\begin{array}{l}\text { Prophylactic immunotherapy } \\
\text { present (vs absent) }\end{array}$ & $\mathbf{0 . 0 4 6}$ & $\mathbf{4 . 7 0 9 ~ ( 1 . 0 3 - 2 1 . 6 2 )}$ \\
\hline $\begin{array}{l}\text { Time from onset of attack to } \\
\text { start of therapy (per 1 d) }\end{array}$ & $\mathbf{0 . 0 1 4}$ & $\mathbf{0 . 9 3 7}(\mathbf{0 . 8 9 - 0 . 9 9 )}$ \\
\hline $\begin{array}{l}\text { First-line apheresis therapy (vs } \\
\text { second-line) }\end{array}$ & $\mathbf{0 . 0 4 7}$ & $\mathbf{1 2 . 2 7 1}(\mathbf{1 . 0 4 - 1 4 4 . 9 1 )}$ \\
\hline \begin{tabular}{l} 
PE (vs IA) \\
\hline \begin{tabular}{l} 
Center number \\
\hline
\end{tabular}
\end{tabular} & 0.107 & $4.946(0.71-34.59)$ \\
\hline
\end{tabular}

Abbreviations: AQP4-ab = anti-aquaporin-4 antibody; $\mathrm{IA}=$ immunoadsorption; $\mathrm{MY}=$ myelitis; $\mathrm{NMO}=$ neuromyelitis optica; NMOSD = NMO spectrum disorder; $\mathrm{ON}=$ optic neuritis; $\mathrm{PE}=$ plasma exchange.

Multivariate generalized estimating equation (GEE) analyses with remission status (complete remission vs partial remission and no remission) of attacks as the dependent variable (working correlation matrix autoregressive of the 1 st order; $\mathrm{n}=79$ patients).

Significant values $(p<0.05)$ are shown in bold.

times as high as the seronegatives, resulting in considerable statistical uncertainty. Therefore, apheresis therapies should also be considered in antibody-negative NMOSD patients.

In NMOSD attacks, escalation and sequence of therapy is decisive, and we have previously observed an advantage for patients treated with apheresis therapies as a first choice when the spinal cord was affected. ${ }^{3}$ Here, we could not show a superiority for one of the 2 different apheresis techniques in the use as first-line therapy. Because of the small numbers of patients with IA therapy included in our study, our data could be biased. A definite comparison between the 2 techniques should be conducted in a prospective randomized clinical trial with appropriate patient numbers. In the absence of further evidence, the decision to use one of both techniques should be made taking availability, side effects, economic factors, and patient preferences into account. ${ }^{24}$

The time between attack onset and start of therapy is decisive, and early initiation of PE was shown to be a predictor of good outcome in studies of CNS demyelination. ${ }^{25,26}$ In a recent study, early initiation of PE within 5 days was identified as a strong predictor for $\mathrm{CR}$ of severe attacks in patients with NMOSD. ${ }^{27}$ Most of our patients received apheresis after a remarkably short period, usually because they had experienced insufficient remission of earlier relapses on steroid treatment and were being treated at tertiary care centers with immediate availability of apheresis therapies. Indeed, time from onset of attack to start of therapy was also a strong predictor in our current study, and an immediate start (within 2 days of symptom onset) was associated with a $40 \%$ rate of $\mathrm{CR}$ as compared to $3.2 \%$ when started later as 6 days after symptom onset. Whether high-dose steroids should be given shortly before or concomitant with apheresis therapy is, however, an open question. In our previous study, first-line exclusive apheresis therapy without high-dose steroid pulse therapy was superior to first-line high-dose steroids in cases of isolated myelitis, but not in $\mathrm{ON}^{3}{ }^{3}$ The concomitant application of high-dose steroids started on the day of admission, and PE initiated "as early as possible" is a procedure reported to be highly efficient in patients with severe NMOSD attacks. ${ }^{16,27}$

Monofocal vs multifocal attack manifestation was also a predictor of $\mathrm{CR}$ with apheresis therapies. However, it has to be noted that monofocal attacks principally have a better chance to recover completely compared with multiregional involvement independent of the chosen attack therapy. ${ }^{3}$

Because of its retrospective nature, our study has limitations. Nevertheless, the analysis comprises one of the largest data sets assembled so far for the analysis of apheresis therapies in NMOSD attacks. Data quality was highly ensured by the "flying doctor" approach as previously described; briefly, 2 neurologists visited the contributing centers and used a predefined standardized evaluation form to assess clinical data. ${ }^{3}$ However, bias cannot be excluded. Particularly the decision on therapy modality, IA or PE, and on the time point when apheresis therapy was started was an individual decision of the treating physician. A center effect could be excluded in our data set, reflecting a high standard and good availability of apheresis therapies in the participating centers. Unfortunately, data of attack severity or tolerability of therapy were not systematically registered and could therefore not be included in our analysis. In addition, delayed improvement may have been missed because remission status was assessed at the conclusion of apheresis, and no prespecified follow-up visits were performed; because this applied to both PE and IA groups, however, it is unlikely to have compromised our main finding. Of interest, concomitant long-term immunotherapy had influence neither on the use of apheresis therapy nor on its effectiveness.

This study has immediate implications for clinical management of NMOSD attacks. The early start of apheresis therapies is strongly recommended. Whether IA or PE is used can be decided individually.

\section{Author contributions}

I. Kleiter and C. Trebst designed the study, analyzed the data, created the figures, conducted literature research, and wrote the manuscript. K-D. Wernecke performed statistical analysis. 
A. Gahlen, N. Borisow and K. Fischer collected ("flying doctor approach") and analyzed the data. K. Hellwig, F. Pache, K. Ruprecht, J. Havla, T. Kümpfel, O. Aktas, H-P. Hartung, M. Ringelstein, C. Geis, C. Kleinschnitz, A. Berthele, B. Hemmer, K. Angstwurm, J-P. Stellmann, S. Schuster, M. Stangel, F. Lauda, H. Tumani, C. Mayer, M. Krumbholz, L. Zeltner, U. Ziemann, R. Linker, M. Schwab, M. Marziniak, F. Then Bergh, U. Hofstadt-van Oy, O. Neuhaus, U. Zettl, J. Faiss, B. Wildemann, F. Paul and S. Jarius collected and analyzed the data. All authors critically revised the manuscript for important intellectual content and approved the final version of the manuscript.

\section{Acknowledgment}

IK and CT had full access to all of the data in the study and take responsibility for the integrity of the data and the accuracy of the data analysis. The authors thank all the patients for participating in the study. The NEMOS cohort/NationNMO is supported by the German Ministry for Education and Research (BMBF) as part of the German Competence Network Multiple Sclerosis (KKNMS; for NEMOS NationNMO-DAB FKZ 01GI1602C to J.S., NationNMO-PAT FKZ 01GI1602B to O.A., and NationNMO-LAB FKZ 01GI1602A to B.W.).

\section{Study funding}

There was no specific funding for the study.

\section{Disclosure}

I. Kleiter received travel funding and/or speaker honoraria from Biogen, Merck, Novartis, Sanofi, and Roche; served as an associate editor for BMC Neurology; consulted for Bayer HealthCare, Chugai, Roche, and Shire; and received research support from Chugai and DiaMed. A. Gahlen received travel funding from Sanofi Genzyme. N. Borisow, K. Fischer, and K-D Wernecke report no disclosures. K. Hellwig served on the scientific advisory boards of Novartis, Genzyme, Teva, Merck, and Roche; received travel funding and/or speaker honoraria from Bayer, Biogen, Merck Serono, Novartis, Teva, Sanofi Genzyme, and Roche; received speaker honoraria from Biogen, Bayer, Teva, Sanofi, Merck, and Novartis; and received research support from Biogen, Bayer, Teva, Merck, and Novartis. F. Pache received travel funding from Genzyme, Bayer, Biogen, ECTRIMS and received research support from Charite-Universitatsmedizin Berlin, Berlin Institute of Health, KKNMS-Bundesministerium für Bildung und Forschung, Ministry in Germany, and Novartis. K. Ruprecht served on the scientific advisory boards of Sanofi-Aventis/Genzyme, Novartis, and Roche; received travel funding and/or speaker honoraria from Bayer, Biogen, Merck Serono, Sanofi-Aventis/Genzyme, Teva, Novartis, and the Guthy Jackson Charitable Foundation; served as an academic editor for PLoS One; received publishing royalties from Elsevier; and received research support from Novartis, Merck Serono, and German Ministry of Education and Research. J. Havla served on the scientific advisory boards of and received speaker honoraria from Novartis, Merck, Roche, Sanofi Genzyme, and
Santhera Pharmaceuticals; received travel funding and/or personal compensation from Novartis and Merck Serono; and received research support from Friedrich-Baur Stiftung. T. Kumpfel received travel funding and/or speaker honoraria from Bayer, Teva, Merck, Novartis, Sanofi-Aventis/Genzyme, CLB Behring, Roche, and Biogen and received grant support from Bayer-Schering AG, Novartis, and Chugai Pharma. O. Aktas served on the scientific advisory board of MedImmune and received travel funding and/or speaker honoraria from Bayer, Novartis, Biogen, Merck Serono, Teva, SanofiGenzyme, Roche, and Almirall. H-P Hartung served on the scientific advisory boards of Novartis, Merck Serono, Teva, Biogen, Roche, Genzyme, Bayer, Sanofi, MedImmune, GeNeuro, Opexa, Octapharma, Receptos, Celgene, and Roche; received speaker honoraria from Biogen, Genzyme, Merck, Novartis, and Roche; and served on the editorial boards of Frontiers Neurology/Immunology, the European Journal of Neurology, Current Opinion in Neurology, and Nature Reviews Neurology. M. Ringelstein received travel funding and/or speaker honoraria from Novartis, Bayer, Biogen, Genzyme, Teva, Merz, Ipsen, and Merck. C. Geis received travel funding from Merck Serono; served as a guest editor for Frontiers Neurology; and received research support from the German Research Council and German Ministry of Education. C. Kleinschnitz reports no disclosures. A. Berthele received travel funding and speaker honoraria from Bayer, Biogen, Genzyme, Merck Serono, Mylan, Novartis, Roche, and Teva. B. Hemmer served on the scientific advisory boards of F. Hoffmann-La Roche, Novartis, Bayer, Genentech, AllergyCare, and TG Therapeutics; received travel funding and/or speaker honoraria from Excemed; served on the editorial boards of JAMA Neurology and the MS Journal; holds a patent for detection of antibodies and T cells against KIR4 in a subpopulation of MS patients and genetic determinants of neutralizing antibodies to interferon $\mathrm{B}$; received research support from Chugai, the German Research Foundation, German Ministry of Education and Research, and EU Horizon 2020; and he or his institution received speaker honoraria from Biogen, Teva, Merck Serono, MedImmune, Novartis, Destin, and Hoffmann-La Roche. K. Angstwurm received travel funding from Alexion, Bayer, Biogen Idec, Merck Serono, Novartis, and Teva and received research support from Alexion, Chugai, Bayer, Biogen, Merck Serono, Novartis, and Roche. J-P Stellmann served on the scientific advisory board of Genzyme; received speaker honoraria from Genzyme and Biogen; received a travel grant from Novartis; and received research support from Biogen, Genzyme, and DFG Research Fellowship. S. Schuster reports no disclosures. M. Stangel served on the scientific advisory boards of Biogen, Baxalta/Shire, CSL Behring, Grifols, MedDay, Merck Serono, Novartis, Roche, Sanofi-Genzyme, and Teva; received travel funding and speaker honoraria from Bayer, Biogen, CSL Behring, Merck Serono, Novartis, Roche, Sanofi-Genzyme, and Teva; served as an academic editor for PLoS One; served on the editorial board of Multiple Sclerosis International; received research support from Biogen, Merck Serono, Novartis, Sanofi-Genzyme, Teva, Deutsche Forschungsgemeinschaft, 
Bundesministerium für Bildung, und Forschung, Volkswagenstiftung. F. Lauda reports no disclosures; H. Tumani served on the scientific advisory boards of Biogen, Siemens Health, Teva, Roche, and Merck; received travel funding and/or speaker honoraria from Merck Serono, Eva, Biogen, Teva, Novartis, Merck Serono, and Novartis; served as section editor for Neurology, Psychiatry and Brain Research; has provided educational presentations for Merck Serono, Bayer, Teva, and Biogen; and received research support from Merck, Teva, Novartis, Sanofi Genzyme, Siemens Health, Biogen, Roche, $\mathrm{BMBF}$, and DMSG. C. Mayer reports no disclosures. M. Krumbholz served on the scientific advisory boards of Novartis, Genzyme, and Roche; received travel funding from Novartis, Biogen, and Celgene; consulted for Genzyme; and received research support from Novartis. L. Zentner reports no disclosures; U. Ziemann served on the scientific advisory board of CorTec; received speaker honoraria from Bayer Vital, Biogen, Bristol-Myers Squibb, Medtronic, and Pfizer; served as editorin-chief for Clinical Neurophysiology, associate editor for the Journal of Neuroscience, deputy editor for Brain Stimulation, and editorial advisory board member for Experimental Brain Research; received publishing royalties from Elsevier, Springer, and Oxford University Press; and received research support from Biogen, Janssen, and Servier. R.A. Linker served on the scientific advisory boards of Biogen, Genzyme, Merck, Novartis, Roche, and Teva; received travel funding and/or speaker honoraria from Biogen, Genzyme, Merck, Novartis, Roche, and Teva; consulted for Biogen, Novartis, and Roche; and received research support from Biogen and Novartis. M. Schwab served on the scientific advisory boards of Merck, Sanofi, Biogen, Novartis, and Roche; received travel funding and/or speaker honoraria from Merck, Sanofi, Biogen, Novartis, and Teva; received academic research support from Novartis; and received research support from the European Community. M. Marziniak received travel funding from the German Migraine Society and the German Multiple Sclerosis Society and received research support from Biogen, Novartis, Bayer Vital, Genzyme/Sanofi-Aventis, Merck Serono, Roche, and Teva; F. Then Bergh received speaker honoraria and consultancy fees as a speaker and advisory from Actelion, Bayer, Biogen, Merck Serono, Novartis, Roche, Sanofi
Genzyme, and Teva; received research support from Actelion, Novartis, German Federal Ministry of Research, and Deutsche Forschungsgmeinschaft; and received travel funding through the employing institution from Bayer Schering, Biogen, and Sanofi Genzyme. U. hofstadt-van Oy served on the scientific advisory boards of Merck and Alexion; received honoraria from Alexion, Bayer, Hormosan, and Zambon; travel funding from AbbVie, Merck, and Sanofi-Genzyme; and received research support from Bayer Schering, Novartis, and Merck. O. Neuhaus reports no disclosures. U.K. Zettl received speaker honoraria and travel funding from Bayer Pharma, Aventis, Teva, Merck Serono, and Biogen Idec; J.H. Faiss received travel funding and/or speaker honoraria from Bayer, Novartis, Biogen, Genzyme, Bohringer, Merck Serono, and Teva and served on the editorial board of Fortschritte Neurologie und Psychiatrie. B.T. Wildemann served on the scientific advisory boards of Novartis, Sanofi Genzyme, and Roche; received personal fees from Biogen, Merck Serono, Novartis, Teva, and Sanofi Genzyme; and received research support from Nundesministerium für Forschung und Technologie, Dietmar Hopp Stiftung, Klaus Tschira Stiftung, Merck Serono, Novartis, and Sanofi Genzyme. F. Paul served on the scientific advisory boards of Novartis and MedImmune; received speaker honoraria and travel funding from Bayer, Novartis, Biogen, Teva, SanofiAventis/Genzyme, Merck Serono, Alexion, Chugai, MedImmune, and Shire; served as an academic editor for PLoS One and an associate editor for Neurology: Neuroimmunology o Neuroinflammation; consulted for Sanofi-Genzyme, Biogen, MedImmune, Shire, and Alexion; and received research support from Bayer, Novartis, Biogen, Teva, Sanofi-Aventis/ Genzyme, Alexion, Merck Serono, the German Research Council, Werth Stiftung of the City of Cologne, German Ministry of Education and Research, Arthur Arnstein Stiftung Berlin, the Arthur Arnstein Foundation Berlin, the Guthy Jackson Charitable Foundation, and NMSS. S. Jarius reports no disclosures; C. Trebst received speaker honoraria from Sanofi Genzyme, Novartis, and Biogen. Full disclosure form information provided by the authors is available with the full text of this article at Neurology.org/NN.

Received May 3, 2018. Accepted in final form July 23, 2018.

Appendix 1 Coinvestigators of the Neuromyelitis Optica Study Group (NEMOS) in alphabetical order. All institutions are in Germany, unless otherwise indicated

\begin{tabular}{|c|c|c|c|}
\hline Name & Affiliation & Role & Contribution \\
\hline Albrecht, P. & University of Düsseldorf & Site investigator & Collected data \\
\hline Ayzenberg, I. & Ruhr-University Bochum & Site investigator & Collected data \\
\hline Bayas, A. & Klinikum Augsburg & Site investigator & Collected data \\
\hline Bellmann-Strobl, J. & Charité University Medicine Berlin & Site investigator & Collected data \\
\hline Bischof, F. & University of Tübingen & Site investigator & Collected data \\
\hline Bittner, S. & Johannes Gutenberg University Mainz & Site investigator & Collected data \\
\hline
\end{tabular}


Appendix 1 Coinvestigators of the Neuromyelitis Optica Study Group (NEMOS) in alphabetical order. All institutions are in Germany, unless otherwise indicated (continued)

\begin{tabular}{|c|c|c|c|}
\hline Name & Affiliation & Role & Contribution \\
\hline Böttcher, T. & Bonhoeffer Klinikum Neubrandenburg & Site investigator & Collected data \\
\hline Brettschneider, J. & University of Ulm & Site investigator & Collected data \\
\hline Buttmann, M. & Caritas Hospital Bad Mergentheim & Site investigator & Collected data \\
\hline DSouza, M. & Charité University Medicine Berlin & Site investigator & Collected data \\
\hline Ettrich, B. & University of Leipzig & Site investigator & Collected data \\
\hline Frank, B. & University of Essen & Site investigator & Collected data \\
\hline Gass, A. & University hospital Mannheim & Site investigator & Collected data \\
\hline Grothe, M. & University of Greifswald & Site investigator & Collected data \\
\hline Guthke. K. & Klinikum Görlitz & Site investigator & Collected data \\
\hline Haarmann, A. & University of Würzburg & Site investigator & Collected data \\
\hline Habedank, E. & University of Göttingen & Site investigator & Collected data \\
\hline Hoffmann, F. & Krankenhaus Martha-Maria Halle & Site investigator & Collected data \\
\hline Hoffmann, 0 . & St. Josefs-Krankenhaus Potsdam & Site investigator & Collected data \\
\hline Hümmert, M.W. & Hannover Medical School & Site investigator & Collected data \\
\hline Junghans, J. & Krankenhaus Martha-Maria Halle & Site investigator & Collected data \\
\hline Kaste, M. & Nordwest-Krankenhaus Sanderbusch & Site investigator & Collected data \\
\hline Kaulen, $\mathbf{B}$. & University of Hamburg & Site investigator & Collected data \\
\hline Kermer, P. & Nordwest-Krankenhaus Sanderbusch & Site investigator & Collected data \\
\hline Kern, P. & Asklepios Klinik Teupitz & Site investigator & Collected data \\
\hline Klotz, L. & University of Münster & Site investigator & Collected data \\
\hline Köhler, w. & Universitätsklinikum Leipzig & Site investigator & Collected data \\
\hline Kolesilova, E. & Asklepios Klinik Teupitz & Site investigator & Collected data \\
\hline Korsen, M. & University of Münster & Site investigator & Collected data \\
\hline Kowarik, M. & University of Tübingen & Site investigator & Collected data \\
\hline Langel, S. & Landeskrankenhaus Rheinhessen & Site investigator & Collected data \\
\hline Lee, D.H. & University of Erlangen & Site investigator & Collected data \\
\hline Liebetrau, M. & St. Josefs-Hospital Wiesbaden GmbH & Site investigator & Collected data \\
\hline Luessi, $\mathrm{F}$. & Johannes Gutenberg University Mainz & Site investigator & Collected data \\
\hline Marouf, w. & University Hospital Bonn & Site investigator & Collected data \\
\hline Meister, S. & University of Rostock & Site investigator & Collected data \\
\hline Melms, A. & University of Erlangen & Site investigator & Collected data \\
\hline Metz, I. & University of Göttingen & Site investigator & Collected data \\
\hline Münch, C. & Charité University Medicine Berlin & Site investigator & Collected data \\
\hline Niehaus, $\mathrm{S}$. & Klinikum Dortmund & Site investigator & Collected data \\
\hline Pawlitzki, M. & University of Magdeburg & Site investigator & Collected data \\
\hline Pellkofer, H. & Ludwig-Maximilians University Munich & Site investigator & Collected data \\
\hline Puhlmann, H.U. & Schlosspark-Klinik Berlin & Site investigator & Collected data \\
\hline
\end{tabular}


Appendix 1 Coinvestigators of the Neuromyelitis Optica Study Group (NEMOS) in alphabetical order. All institutions are in Germany, unless otherwise indicated (continued)

\begin{tabular}{|c|c|c|c|}
\hline Name & Affiliation & Role & Contribution \\
\hline Pul, R. & University of Essen & Site investigator & Collected data \\
\hline Retzlaf, N. & University of Rostock & Site investigator & Collected data \\
\hline Riedlinger, A. & Asklepios Klinik Teupitz & Site investigator & Collected data \\
\hline Rommer, P. & Medical University of Vienna, Austria & Site investigator & Collected data \\
\hline Röpke, L. & University of Jena & Site investigator & Collected data \\
\hline Rostásy, K. & Vestische Caritas-Kliniken GmbH & Site investigator & Collected data \\
\hline Rückriem, L. & MediClin Hedon-Klinik Lingen (Ems) & Site investigator & Collected data \\
\hline Ruschil, C. & University of Tübingen & Site investigator & Collected data \\
\hline Schippling, S. & University of Zürich, Switzerland & Site investigator & Collected data \\
\hline Senel, M. & University of Ulm & Site investigator & Collected data \\
\hline Sieb, J.P. & Helios Hanseklinikum Stralsund & Site investigator & Collected data \\
\hline Sommer, C. & University of Würzburg & Site investigator & Collected data \\
\hline Spreer, A. & Johannes Gutenberg University Mainz & Site investigator & Collected data \\
\hline Steinbrecher, A. & Helios Klinikum Erfurt & Site investigator & Collected data \\
\hline Stephanik, H. & University of Magdeburg & Site investigator & Collected data \\
\hline Stoppe, M. & University of Leipzig & Site investigator & Collected data \\
\hline Süße, M. & University of Greifswald & Site investigator & Collected data \\
\hline Tackenberg, $\mathrm{B}$. & University of Marburg & Site investigator & Collected data \\
\hline Tünnerhoff, J. & University of Tübingen & Site investigator & Collected data \\
\hline Veauthier, C. & Charité University Medicine Berlin & Site investigator & Collected data \\
\hline Walter, A. & Klinikum Herford & Site investigator & Collected data \\
\hline Wandinger, K.P. & University Medical center Schleswig-Holstein Campus Lübeck & Site investigator & Collected data \\
\hline Warnke, C. & University of Köln & Site investigator & Collected data \\
\hline Weber, M.S. & University of Göttingen & Site investigator & Collected data \\
\hline Weissert, $\mathbf{R}$. & University of Regensburg & Site investigator & Collected data \\
\hline Wiendl, $\mathbf{H}$. & University of Münster & Site investigator & Collected data \\
\hline Wilke, C. & Nervenzentrum Potsdam & Site investigator & Collected data \\
\hline Winkelmann, A. & University of Rostock & Site investigator & Collected data \\
\hline Yalachkov, Y. & University of Frankfurt & Site investigator & Collected data \\
\hline Young, $\mathrm{K}$. & University of Hamburg & Site investigator & Collected data \\
\hline Zentner, C. & Krankenhaus Martha-Maria Halle & Site investigator & Collected data \\
\hline Zipp, F. & Johannes Gutenberg University Mainz & Site investigator & Collected data \\
\hline
\end{tabular}

\section{References}

1. Jarius S, Ruprecht K, Wildemann B, et al. Contrasting disease patterns in seropositive and seronegative neuromyelitis optica: a multicentre study of 175 patients. J Neuroinflammation 2012;9:14

2. Trebst C, Jarius S, Berthele A, et al. Update on the diagnosis and treatment of neuromyelitis optica: recommendations of the Neuromyelitis Optica Study Group (NEMOS). J Neurol 2014;261:1-16.

3. Kleiter I, Gahlen A, Borisow N, et al. Neuromyelitis optica: evaluation of 871 attacks and 1153 treatment courses. Ann Neurol 2016;79:206-216.
4. Bronzlik P, Toto S, Kielstein J, Schmidt B, Stangel M, Trebst C. Therapeutic plasma exchange and immunoadsorption therapy in neurological diseases. Eur Neu J 2011;3: $56-61$.

5. Braun N, Bosch T. Immunoadsorption, current status and future developments. Expert Opin Investig Drugs 2000;9:2017-2038

6. Zekeridou A, Lennon VA. Aquaporin-4 autoimmunity. Neurol Neuroimmunol Neuroinflamm 2015;2:e110. doi: 10.1212/NXI.0000000000000110.

7. Matic G, Bosch T, Ramlow W. Background and indications for protein A-based extracorporeal immunoadsorption. Ther Apher 2001;5:394-403. 
8. Staudt A, Dorr M, Staudt Y, et al. Role of immunoglobulin G3 subclass in dilated cardiomyopathy: results from protein A immunoadsorption. Am Heart J 2005;150: 729-736.

9. Baggi F, Ubiali F, Nava S, et al. Effect of IgG immunoadsorption on serum cytokines in MG and LEMS patients. J Neuroimmunol 2008;201-202:104-110.

10. Bulut D, Creutzenberg G, Mugge A. The number of regulatory T cells correlates with hemodynamic improvement in patients with inflammatory dilated cardiomyopathy after immunoadsorption therapy. Scand J Immunol 2013;77: 54-61.

11. Wingerchuk DM, Lennon VA, Pittock SJ, Lucchinetti CF, Weinshenker BG. Revised diagnostic criteria for neuromyelitis optica. Neurology 2006;66:1485-1489.

12. Wingerchuk DM, Lennon VA, Lucchinetti CF, Pittock SJ, Weinshenker BG. The spectrum of neuromyelitis optica. Lancet Neurol 2007;6:805-815.

13. Dahmen G, Ziegler A. Generalized estimating equation on controlled clinical trials: hypotheses testing. Biomed J 2004;46:214-232.

14. Weinshenker BG, O'Brien PC, Petterson TM, et al. A randomized trial of plasma exchange in acute central nervous system inflammatory demyelinating disease. Ann Neurol 1999;46:878-886.

15. Watanabe $\mathrm{S}$, Nakashima I, Misu T, et al. Therapeutic efficacy of plasma exchange in NMO-IgG-positive patients with neuromyelitis optica. Mult Scler 2007;13: $128-132$.

16. Bonnan M, Valentino R, Olindo S, Mehdaoui H, Smadja D, Cabre P. Plasma exchange in severe spinal attacks associated with neuromyelitis optica spectrum disorder. Mult Scler 2009;15:487-492.

17. Merle H, Olindo S, Jeannin S, et al. Treatment of optic neuritis by plasma exchange (add-on) in neuromyelitis optica. Arch Ophthalmol 2012;130:858-862.
18. Kim SH, Kim W, Huh SY, Lee KY, Jung IJ, Kim HJ. Clinical efficacy of plasmapheresis in patients with neuromyelitis optica spectrum disorder and effects on circulating antiaquaporin-4 antibody levels. J Clin Neurol 2013;9:36-42.

19. Koziolek M, Muhlhausen J, Friede T, et al. Therapeutic apheresis in pediatric patients with acute CNS inflammatory demyelinating disease. Blood Purif 2013;36:92-97.

20. Lim YM, Pyun SY, Kang BH, Kim J, Kim KK. Factors associated with the effectiveness of plasma exchange for the treatment of NMO-IgG-positive neuromyelitis optica spectrum disorders. Mult Scler 2013;19:1216-1218.

21. Yasuda T, Mikami T, Kawase Y. Efficacy of tryptophan immunoadsorption plasmapheresis for neuromyelitis optica in two cases. Ther Apher Dial 2015;19:411-412.

22. Abboud H, Petrak A, Mealy M, Sasidharan S, Siddique L, Levy M. Treatment of acute relapses in neuromyelitis optica: steroids alone versus steroids plus plasma exchange. Mult Scler 2016;22:185-192.

23. Magana SM, Keegan BM, Weinshenker BG, et al. Beneficial plasma exchange response in central nervous system inflammatory demyelination. Arch Neurol 2011;68: 870-878.

24. Kleiter I, Gold R. Present and future therapies in neuromyelitis optica spectrum disorders. Neurotherapeutics 2016;13:70-83.

25. Keegan M, Pineda AA, McClelland RL, Darby CH, Rodriguez M, Weinshenker BG Plasma exchange for severe attacks of CNS demyelination: predictors of response. Neurology 2002;58:143-146.

26. Llufriu S, Castillo J, Blanco Y, et al. Plasma exchange for acute attacks of CNS demyelination: predictors of improvement at 6 months. Neurology 2009;73:949-953.

27. Bonnan M, Valentino R, Debeugny S, et al. Short delay to initiate plasma exchange is the strongest predictor of outcome in severe attacks of NMO spectrum disorders. J Neurol Neurosurg Psychiatry 2018;89:346-351. 


\section{Neurology \\ Neuroimmunology \& Neuroinflammation}

\section{Apheresis therapies for NMOSD attacks: A retrospective study of 207 therapeutic interventions \\ Ingo Kleiter, Anna Gahlen, Nadja Borisow, et al. \\ Neurol Neuroimmunol Neuroinflamm 2018;5; \\ DOI 10.1212/NXI.0000000000000504}

This information is current as of September 26, 2018

\section{Updated Information \& \\ Services}

References

Citations

Subspecialty Collections

Permissions \& Licensing

Reprints including high resolution figures, can be found at:

http://nn.neurology.org/content/5/6/e504.full.html

This article cites 27 articles, 2 of which you can access for free at: http://nn.neurology.org/content/5/6/e504.full.html\#\#ref-list-1

This article has been cited by 7 HighWire-hosted articles: http://nn.neurology.org/content/5/6/e504.full.html\#\#otherarticles

This article, along with others on similar topics, appears in the following collection(s):

Devic's syndrome

http://nn.neurology.org//cgi/collection/devics_syndrome

Information about reproducing this article in parts (figures,tables) or in its entirety can be found online at:

http://nn.neurology.org/misc/about.xhtml\#permissions

Information about ordering reprints can be found online:

http://nn.neurology.org/misc/addir.xhtml\#reprintsus

Neurol Neuroimmunol Neuroinflamm is an official journal of the American Academy of Neurology.

Published since April 2014, it is an open-access, online-only, continuous publication journal. Copyright

Copyright $\odot 2018$ The Author(s). Published by Wolters Kluwer Health, Inc. on behalf of the American

Academy of Neurology.. All rights reserved. Online ISSN: 2332-7812.

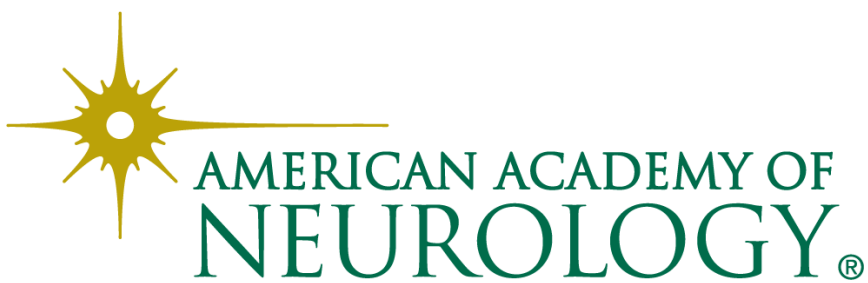

